\title{
FORMATION MECHANISMS OF SNOW CRYSTALS AT LOW TEMPERATURE
}

\author{
by
}

\author{
Noboru Sato and Katsuhiro KikUChI
}

Department of Geophysics, Faculty of Science, Hokkaido University, Sapporo, Japan 060

\section{ABSTRACT}

To study crystal shapes, and formation and growth mechanisms of snow crystals formed below $-20^{\circ} \mathrm{C}$, a new type of diffusion chamber was constructed. Using this chamber, different kinds of "peculiar shaped" crystals previously observed in nature have been produced, together with normal types of snow crystals. Gohei twins, one of the most typical polycrystalline shapes in nature, have been produced artificially. The vapor pressure was at or near water saturation at the time of nucleation. Analysis of photomicrographs and replicas of Gohei twins that were replicated in the polar regions show that the number frequency of the tip angle has a maximum frequency at about $77^{\circ}$ and a minor one at about $54^{\circ}$.

On the basis of these results, a formation mechanism for some Gohei twins is proposed in this paper.

\section{INTRODUCTION}

Different kinds of peculiar shapes of snow crystals have been discovered in the Antarctic, where they were first reported by Kikuchi $(1969,1970)$. Most of them have also been observed in the Arctic (Kikuchi and Magono 1978). Because they form at temperatures colder than $-20^{\circ} \mathrm{C}$, they were called "Snow crystals of cold temperature types". The main external shapes of these peculiar crystals are "Tetragon", "Seagull", and "Gohei" types: almost all are polycrystalline.

This work proposes a formation mechanism for Gohei twins, the most typical polycrystalline form. "Gohei" is a Japanese word for the pendant paper strips hanging from a sacred rope at a Shinto shrine. There is a strong contrast between the individual components of these crystals under a polarizing microscope with a sensitive color plate.

A Gohei twin is shown schematically in Figure 1, and defined as follows: (1) it is polycrystalline; (2) the tip is

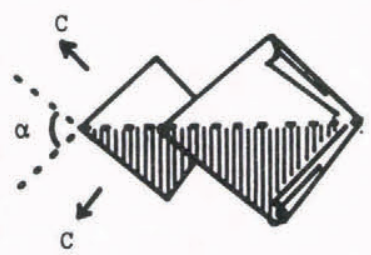

Fig.1. Schematic figure of Gohei twins.

closed; (3) the shape is symmetrical with respect to the center line of the crystal; (4) the crystal grows in tiers. The tip angle of the Gohei twin is designated $\alpha$.

\section{EXPERIMENTAL}

\section{Experimental method}

A thermal diffusion cold chamber designed to investigate the peculiar shaped snow crystals in detail (Figure 2) was mounted on the stage of an inverted microscope. Diameters of upper and lower plates in the chamber were $40 \mathrm{~mm}$ and their separation was $6 \mathrm{~mm}$. Liquid nitrogen from the jar was forced into the plates by pressure of the nitrogen gas. By controlling flow rate and using a heater imbedded in the lower plate, the temperatures $\mathrm{Tt}$ and $\mathrm{Tb}$ of the plates were maintained

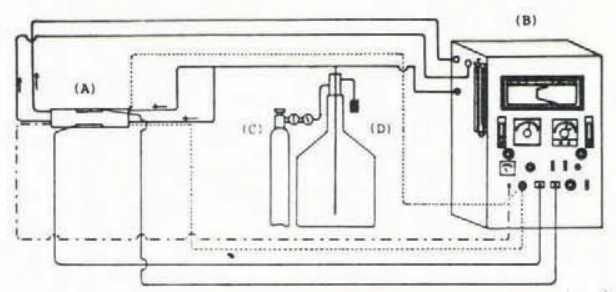

(a)

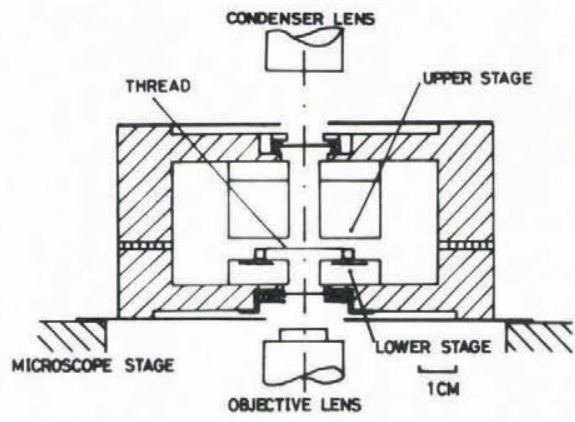

(b)

Fig.2. (a) Schematic diagram of experimental arrangement: (A) cold chamber (B) temperature controller (C) nitrogen gas vessel (D) jar of liquid nitrogen. (b) Cold chamber for growing snow crystals.

independently at any desired value down to $-70^{\circ} \mathrm{C}$; their cooling rates could also be controlled. Plate temperatures were measured by fine thermocouples attached to the surfaces: the surfaces were lined with ice sheets, formed by freezing distilled and deionized water, which were the source of water vapor to induce snow crystal growth. Windows $8 \mathrm{~mm}$ in diameter in the center of the plates allowed the growing snow crystals to be observed by transmitted light. The windows were warmed by heated nitrogen gas to prevent frosting.

Before starting an experiment, two or three fine silk threads 5 to $20 \mu \mathrm{m}$ in diameter and about $1.5 \mathrm{~mm}$ apart, were stretched horizontally through the center of the chamber on a plastic frame. The temperature near the thread, Ta, was measured with a fine thermocouple. The temperature difference between the upper and lower ice sheets, $\Delta \mathrm{T}$, was controlled in such a way that snow crystals nucleated on the threads. If $\Delta \mathrm{T}$ was too large, the threads were usually covered all over with hoar frost. Isolated crystals formed when $\Delta \mathrm{T}$ was just right. After the appearance of crystals on the threads, $\mathrm{Tt}$ and $\mathrm{Tb}$ were fixed and steady state conditions were rapidly achieved. The snow crystals grew on the threads under constant temperature conditions.

Formation conditions of artificial snow crystals

Temperature profile, measured at intervals of one millimeter with a very fine thermocouple, were almost 
linear. From observations of the state of thread, it was found that the artificial snow crystals passed through a liquid phase at the nucleation stage: therefore the water vapor pressure was at or near water saturation. This probably decreased as the crystal grew, because many crystals grew on a thread, each crystal competing for water vapor.

To estimate saturation with respect to ice, linear growth rates of the columnar crystals were measured and converted to mass growth rates using $\mathrm{m}=1.3 \mathrm{a}^{2} 1$, where $\mathrm{m}$ is the mass in milligrams, a, the radius, and 1 , the length of the column in millimeters (Higuchi 1956). The rate of increase of the crystal mass $\mathrm{m}$ is

$$
\frac{\mathrm{dm}}{\mathrm{dt}}=4 \pi \mathrm{CD}\left(\rho_{\infty}-\rho_{\mathrm{S}}\right)
$$

where C is the electrostatic capacity of the crystal, D the diffusion coefficient of water vapor in air, $\rho_{s}$ the vapor density at the surface of the growing crystal and $\rho_{\infty}$ its value at a great distance from the ice crystal in the undisturbed field (Houghton 1950). This equation does not take into account the influence of interface kinetics and considers only the influence of the water vapor field.

Vapor pressure can be estimated from this equation. An example at $\mathrm{Ta}=-35^{\circ} \mathrm{C}, \Delta \mathrm{T}=20^{\circ} \mathrm{C}$ is shown in Figure 3. The ordinate and abscissa show supersaturation with respect to ice and the lapse of time from the starting of the experiment, respectively. The snow crystals were

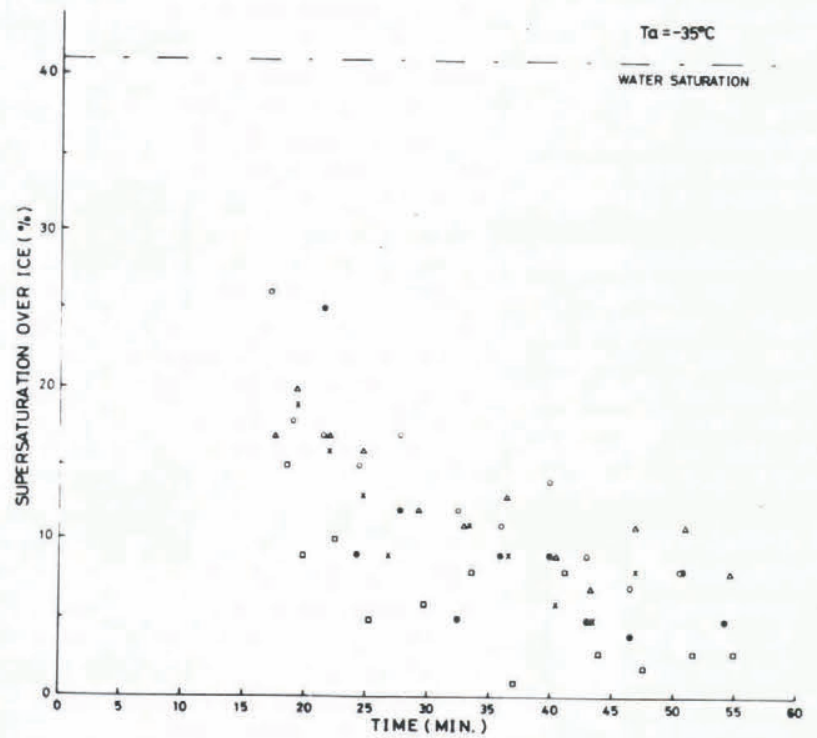

Fig.3. Supersaturation in cold chamber as a function of time.

nucleated on the thread at about $t=15$ minutes. The same symbol in this figure shows the same column growing as time progressed. This figure shows how the supersaturation decreased with time: it was about $10 \%$ after 10 minutes had elapsed from the nucleation of crystals. If the influence of the interface kinetics is taken into account, supersaturation will be increased about two fold (Beckmann 1982). The supersaturation obviously depends also on the crystal spacing along the threads.

\section{Artificial Gohei twins}

During experiments carried out under different conditions in the cold chamber, many kinds of ice crystals with peculiar shapes were produced; Gohei twins were among them (Figure 4(a) and (b)). The crystal in Figure 4(a) grew at $\mathrm{Ta}=-40^{\circ} \mathrm{C}$. Extended planes are prism planes (10i0). Using crossed nicols on this crystal, it was clear that the c-axis orientations were different on either side of the center line: tip angle $\alpha$ is $78^{\circ}$. This crystal grew a part of a combination of bullets. On the other hand, the tip angle $\alpha$ of crystal (b) is $55^{\circ}:$ this grew at $-32^{\circ} \mathrm{C}$ as part of a combination of bullets.
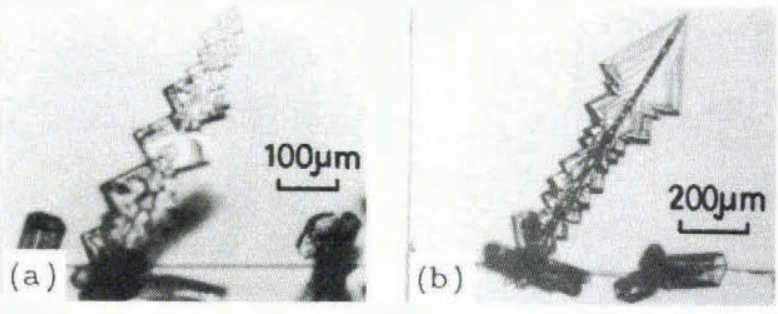

(c)
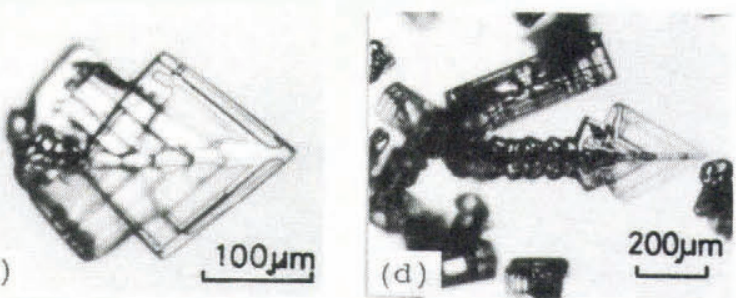

Fig.4. Photographs of Gohei twins. (a) and (b): artificial; (c) and (d): natural.

\section{ANALYSIS}

Kikuchi observed snow crystals at Syowa Station (1968), South Pole Station (1975, 1978), and Inuvik, NWT, Arctic Canada (1977, 1979-80), recording shapes of snow crystals by photomicrographs and replicating them on glass slides using Formvar solution. To determine the presence or absence of preferred tip angles in Gohei twins, photomicrographs and replicas of the crystals fom twins, regions were examined. 116 crystals were examined, of which 53 were recorded on photomicrographs. The results are shown in Figure 5. The number frequency of the tip angles show a strong maximum frequency at about $77^{\circ}$ and

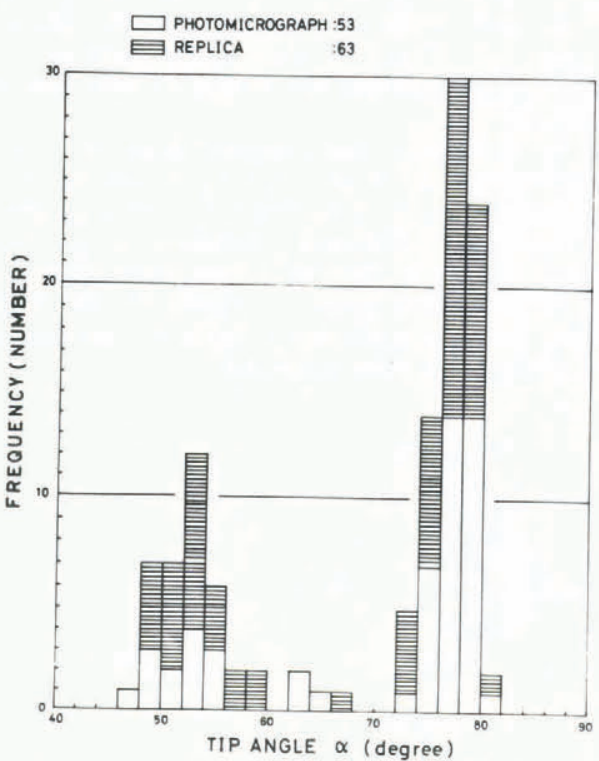

Fig.5. Frequency histograms of the tip angle $\alpha$.

a minor peak at about $54^{\circ}$. A possible third peak, very weak, is at about $66^{\circ}$. Two examples of crystals observed in the polar regions are in Figure 4 (c) and (d).

\section{DISCUSSION}

The formation conditions of Gohei twins are becoming clear from experiments and observations of the natural snow crystals. (1) A preference exists in the tip angle of Gohei twins; (2) Gohei twins grow as a part of a combination of bullets, and (3) water vapor pressure at nucleation is at or near water saturation. We therefore concluded that Gohei twins grow from frozen cloud droplets. If, when a droplet freezes, the prism planes of two adjacent crystals grow in 


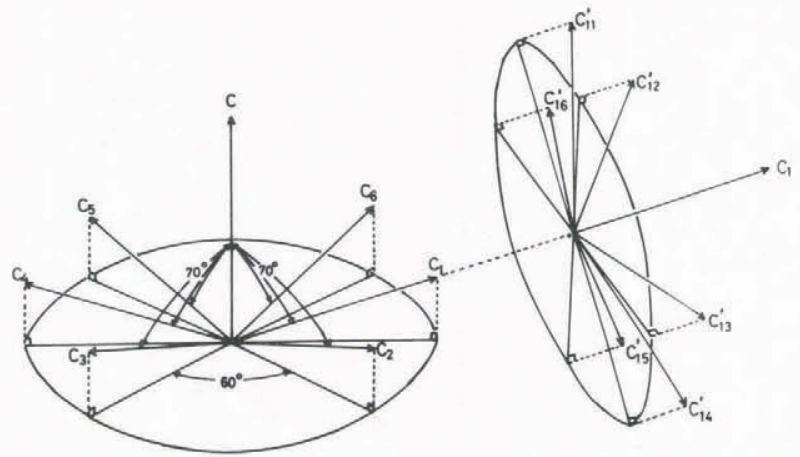

Fig.6. An arrangement of the c-axes.

such a way that they cross at a small angle, the grain boundary grows out as a Gohei twin.

The preferred angular relations between the c-axes can be explained following Uyeda and Kikuchi (1982). Misorientations between neighbouring crystals occur according to the cubic structure model of a thin layer on the basal plane $(0001)$ of an ice crystal (Kobayashi and others 1976). When polycrystallization commences on the basal plane of a hexagonal ice crystal, the directions of the c-axes $\mathrm{C}_{1}, \mathrm{C}_{2} \ldots$ and $\mathrm{C}_{6}$ indicated on the left hand side of Figure 6 would be found in the water droplet. Further, if a cubic structure was formed again on a basal plane of one of the six new crystals, with c-axes $C_{1}, C_{2} \ldots$ and $C_{6}$, six new directions of the c-axes would be made as shown on the right hand side of Figure 6.

Here six new directions $C^{\prime}{ }_{11}, C^{\prime}{ }_{12}$... and $C^{\prime}{ }_{16}$, form around $C_{1}$. Similarly, six new c-axes form on each of $\mathrm{C}_{2}, \mathrm{C}_{3} \ldots$ and $\mathrm{C}_{6}$. The six new c-axes on $\mathrm{C}_{2}, \mathrm{C}_{3} \ldots$ and $\mathrm{C}_{6}$ are designated $\mathrm{C}^{\prime}{ }_{21}, \mathrm{C}_{22}^{\prime} \ldots$ and $\mathrm{C}_{26}^{\prime}, \mathrm{C}^{\prime}{ }_{31}, \mathrm{C}^{\prime} \mathrm{C}_{32} \ldots$ . and $C^{\prime}{ }_{36}, \ldots$ and $C^{\prime}{ }_{61}, C_{62}^{\prime} \ldots$ and $C^{\prime}{ }_{66}$. The six groups of six new $c$-axis orientations are designated $C_{1}$ ', $\mathrm{C}_{2}{ }^{\prime}, \ldots$ and $\mathrm{C}_{6}{ }^{\prime}$. Thus, 36 new c-axis directions can be formed. Axial angles between the c-axes of any two crystals can be calculated.

Next, in each case the crossing angle of two prism planes was calculated. In Figure $7, \mathrm{C}^{\prime}{ }_{1 j}$ is one direction and $a_{1 m}$ is an $a$-axis direction. Selecting $C^{j_{1 j}}$ and $a_{1 m}$, one prism plane is determined. Similarly, selecting $C^{\prime}{ }_{k l}^{\prime}$ and $a_{k n}$ ' another prism plane is decided. The side view of the intersection of two prism planes is shown on the right hand side in Figure 7. A supplementary angle of this intersection of the prism planes, $\boldsymbol{\beta}$, was calculated.

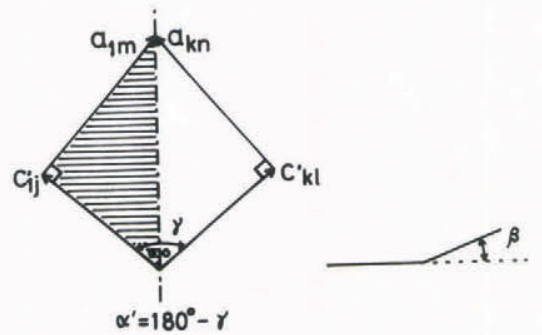

Fig.7. Angles of $\alpha^{\prime}$ and $\boldsymbol{\beta}$ of Gohei twins.

We assumed that a combination of two prism planes which satisfied the next two conditions could grow as a Gohei twin: (1) $\beta<20^{\circ}$, and (2) two c-axes are symmetric with respect to the crossing line of two prism planes. These conditions were chosen because the Gohei twins were observed to be almost flat and symmetric with respect to the center line of the crystal. The angle $\alpha^{\prime}$ of a Gohei twin is the supplement of the angle between c-axes of the two crystals, $y$ in Figure 7. $\alpha^{\prime}$ corresponds to the tip angle $\alpha$. The combinations of the orientations satisfying the two conditions above are listed in Table $1 . \alpha^{\prime}=78^{\circ}$ and $\beta=$ $13^{\circ}, \alpha^{\prime}=56^{\circ}$ and $\beta=19^{\circ}, \alpha^{\prime}=68^{\circ}$ and $\beta=18^{\circ}\left(\alpha^{\prime}=\right.$ $66^{\circ}$ and $\left.\beta=11^{\circ}\right)$, which were marked by asterisks in Table 1 , correspond to the observed peaks at $77^{\circ}, 54^{\circ}$ and $66^{\circ}$.
TABLE 1, CALCULATION RESULTS OF THE ANGLES OF $\alpha^{\prime}$ AND $\beta$.

\begin{tabular}{|c|c|c|}
\hline & $\alpha^{\prime}$ & $\beta$ \\
\hline$C_{i}^{\prime}-C_{1}^{\prime}$ & $* 56^{\circ}$ & $19^{\circ}$ \\
& $39^{\circ}$ & $19^{\circ}$ \\
\hline$C_{1}^{\prime}-C_{2}^{\prime}$ & $* 66^{\circ}$ & $11^{\circ}$ \\
$C_{1}^{\prime}-C_{6}^{\prime}$ & $* 78^{\circ}$ & $13^{\circ}$ \\
& $32^{\circ}$ & $16^{\circ}$ \\
& $* 56^{\circ}$ & $19^{\circ}$ \\
& $39^{\circ}$ & $19^{\circ}$ \\
\hline$C_{1}^{\prime}-C_{3}^{\prime}$ & $* 66^{\circ}$ & $11^{\circ}$ \\
$C_{1}^{\prime}-C_{5}^{\prime}$ & $32^{\circ}$ & $16^{\circ}$ \\
& $* 56^{\circ}$ & $19^{\circ}$ \\
& $39^{\circ}$ & $19^{\circ}$ \\
\hline$C_{i}^{\prime}-C_{4}^{\prime}$ & $* 66^{\circ}$ & $11^{\circ}$ \\
& $* 68^{\circ}$ & $18^{\circ}$ \\
& $* 56^{\circ}$ & $19^{\circ}$ \\
& $39^{\circ}$ & $19^{\circ}$ \\
\hline
\end{tabular}

\section{CONCLUSIONS}

Using a new diffusion type cold chamber, several kinds of peculiar shaped crystals corresponding to types observed in nature have been grown, among them Gohei twins which are the most common peculiar shapes. They were nulceated at or near water saturation. Tip angles of Gohei twins observed in the polar regions were measured: the number frequency of the tip angles has a major peak at about $77^{\circ}$ and a minor one at about $54^{\circ}$.

Assuming that a crystal briefly took a cubic structure twice on basal planes of crystals just nucleated in a supercooled cloud droplet, these peaks in the tip angle frequency may be explained. However, other peaks that are predicted in this way were not observed.

\section{ACKNOWLEDGMENTS}

The authors thank Dr C A Knight, NCAR, for carefully reviewing the manuscript. A part of this work was made under Project No. 00542018 of "Studies on Snow Crystals of Cold Temperature Types" from 1980 to 1982 under the Grant-in-Aid for Scientific Research (A), the Ministry of Education, Science and Culture of Japan, for which they express their sincere thanks.

\section{REFERENCES}

Beckmann W 1982 Interface kinetics of the growth and evaporation of ice single crystals from the vapour phase III, Measurements under partial pressures of nitrogen. Journal of Crystal Growth 58: 443-451

Higuchi K 1956 A new method for the simultaneous observation of a large number of falling snow particles. Journal of Meteorology 13: 274-278

Houghton H G 1950 A preliminary quantitative analysis of precipitation mechanisms. Journal of Meteorology 7: 363-369

Kikuchi K 1969 Unknown and peculiar shapes of snow crystals observed at Syowa Station, Antarctica. Journal of the Faculty of Science, Hokkaido University Ser. VII(3): 99-116

Kikuchi K 1970 Peculiar shapes of solid precipitation observed at Syowa Station, Antarctica. Journal of the Meteorological Society of Japan 48: 243-249

Kikuchi K, Magono C 1978 General description of the meteorological conditions and shapes of snow crystals during the observation period at Inuvik, NWT, Canada. In Magono, C (ed) Snow crystals in Arctic Canada. Hokkaido University, Japan: 4-27

Kobayashi T, Furukawa Y, Takahashi T, Uyeda H 1976 Cubic structure models at the junctions in polycrystalline snow crystals. Journal of Crystal Growth 35: 262-268

Uyeda H, Kikuchi K 1982 Some considerations on combination of bullets which have the axial angle between the c-axes of $90^{\circ}$. Journal of the Faculty of Science, Hokkaido University, Ser VII(7): 145-157 